\title{
Polymeric membrane materials for nitrogen production from air: a process synthesis study
}

\author{
M. Bozorg ${ }^{\mathrm{a}, \mathrm{b}, \mathrm{c}}$, B. Addis ${ }^{\mathrm{a}}$, V. Picciallic ${ }^{\mathrm{c}}$ Álvaro A. Ramírez-Santos ${ }^{\mathrm{b}}$, C. Castel $^{\mathrm{b}}, \mathrm{I}_{\text {. Pinnau }}^{\mathrm{d}}$, \\ E. Favre ${ }^{\text {b,e }}$ \\ ${ }^{a}$ Université de Lorraine, CNRS, LORIA, F-54000 Nancy, France \\ ${ }^{b}$ Université de Lorraine, CNRS, LRGP, F-54000 Nancy, France \\ ${ }^{c}$ Dipartimento di Ingegneria Civile e Ingegneria Informatica, Universitá degli Studi di Roma Tor Vergata, \\ viale del Politecnico 1, 00133 Rome, Italy \\ ${ }^{d}$ Advanced Membranes and Porous Materials Research Center, King Abdullah University of Science and \\ Technology, Thuwal, Saudi Arabia \\ ${ }^{e}$ Corresponding author
}

\begin{abstract}
Nitrogen production from air by membrane gas separation processes is a mature technology which is applied in numerous industrial sectors (chemical, food, aeronautics, space..). Depending on the nitrogen purity requirements (typically between 90 and 99.9\%), single stage or multistage membrane process configurations are used. A very large number of advanced membrane materials have been recently reported, showing increasing permeability and/or selectivity for air separation applications (i.e. trade-off limits of dense polymeric materials for the $\mathrm{O}_{2} / \mathrm{N}_{2}$ gas pair) compared to the commercially available membranes. The interest of these new materials in terms of nitrogen production cost and their impact in terms of process configuration are reported through a process synthesis study. Based on a tailor made optimization methodology and program, the production cost and associated optimal process configuration are first identified for two standard $\mathrm{O}_{2} / \mathrm{N}_{2}$ separation membranes at four different levels of $N_{2}$ purity $(90,95,99,99.9 \%)$. The same strategy is then performed with advanced trade-off membrane materials, with the possibility to combine different materials in multistaged systems. The impact in terms of nitrogen production cost for the different purities and the corresponding optimal membrane materials and process configurations are discussed. Surprisingly, a medium membrane selectivity combined to a high permeability is shown to systematically offer the best set of performances, for mono or multistaged systems. Vacuum operation and recycling loops are shown to generate lower $N_{2}$ production costs.

Keywords: Nitrogen, Membrane, Process, Synthesis, Optimization, Materials, Cost
\end{abstract}




\section{Introduction}

Membrane processes are one of the key technologies for gas separation applications [1, 2]. Hydrogen purification, natural gas treatment, Volatile Organic Compounds recovery, gas drying are increasingly applied into different industrial sectors thanks to membrane units [3], but the number one market of membrane gas separations remains nitrogen production from air (Nitrogen Enriched Air, NEA) [4]. Starting form a nitrogen content in air of approximately $79 \%$, a membrane gas separation unit indeed enables purity levels of $90 \%$ or more to be easily obtained. A membrane process is continuous (no regeneration step), it does not involve chemicals, does not generate waste, offers intensification possibilities, it is modular (ease of scale up) and does not imply complex operations (such as cycles) [5]. These arguments are of major interest for on board systems (e.g. boats, planes, space applications). But membrane units are also used for large capacity industrial applications, such as blanketing for explosive environments (hydrocarbons and solvent storage), or generation of inert atmospheres (e.g. non oxidizing) for chemicals or materials production, among others [1]. Nitrogen production by membranes is also favorable because the target compound is less permeable than the air compounds to be eliminated $\left(\mathrm{O}_{2}, \mathrm{H}_{2} \mathrm{O}, \mathrm{CO}_{2}\right)$. As a consequence, a purified stream of nitrogen can be continuously produced on the retentate (i.e. high pressure) side. In a large number of situations, no additional purification or recompression step are needed.

Generally speaking, membrane processes are more interesting for moderate purity, and low to moderate capacity $N_{2}$ applications [6]. Cryogeny is the best available technology for high purity (e.g. $>99.99 \%$ ) high capacity (e.g. $>200$ ton per day) units. Adsorption processes are favored for intermediate purity and capacity [7]. The improvements in membrane materials and process designs have enlarged the domain of application of membranes through the years. Commercial membrane materials remain almost exclusively based on dense polymers, which should ideally combine a high selectivity and high permeability [8]. Hundreds of structures have been investigated in order to maximize these two characteristics [9-11] but a trade-off limit, based on a concept suggested by Robeson [12], exists between the two. Few membrane materials for nitrogen production applications are commercially available today (i.e. polysulfones, polyimides, polyphenylene oxide)[4]. The level of performances of these materials is below the trade-off limits and the interest of advanced materials, with performances close to the trade-off limit, in terms of $N_{2}$ production cost, is logically a key question. To our knowledge however, no study addressed so far the rigorous analysis of the impact of advanced membrane materials for nitrogen production. Such a piece of work should ideally combine a large choice of membrane materials together with modern process design tools, in order to identify the most promising production strategies.

In this study, the production cost of NEA for four different levels of purity is analyzed (90, 95, 99 and 99.9\%). In a first step, the minimal cost and optimal process configuration with currently commercially available membrane materials is identified thanks to a tailor made process synthesis package, recently developed for carbon capture applications [13]. The optimal structure (number of stages, compression or vacuum operation, multistage configuration) and the associated nitrogen production costs are thus obtained and will correspond to the reference case. In a second step, the possibilities of advanced trade-off materials are explored thanks to a novel, generic approach: the minimal production cost for a given nitrogen purity is identified based on systematic screening of trade-off membrane performances and process 
configurations (including compression, vacuum pumping and recycling loops), with two options: same optimal trade-off membrane used for all membrane stages or possibility to use a different trade-off membrane material in each membrane stage.

The objectives of the study are to provide an answer to the following questions:

- How does nitrogen purity impact process configuration and cost with currently commercially available membranes?

- What are the best process configurations and the associated costs with advanced membrane materials (i.e. trade-off limit performances)?

- What is the best membrane material for each nitrogen purity level within the trade-off limits (i.e. high selectivity or high permeability)?

- Is there an interest to combine different membrane materials into multistaged units for nitrogen production?

This set of results is expected to provide clear guidelines for air separation membrane developments and also help to better evaluate the interplay between materials performances, process design and production cost.

\section{PROCESS SYNTHESIS METHODOLOGY APPLIED TO MEMBRANE GAS SEPARATIONS AND NEA PRODUCTION}

\subsection{Process synthesis and membrane gas separations: overall methodology}

The optimal process designs detailed hereafter are obtained by means of a tailor made computer program specifically designed for membrane gas separations. Starting from separation specifications (feed composition, permeate and/or retentate composition), the optimal process flow-sheet and the associated operating conditions are identified thanks to a global optimization algorithm with an objective cost function. The overall process synthesis framework is summarized in Figure 1 . 


\section{Process synthesis possibilities:}

1. Fixed pre-selected membrane permeances for all stages

2. Uniform optimal membrane limited by Robeson's upper bound for all stages

3. Independent optimal membrane limited by Robeson's upper bound for each stage

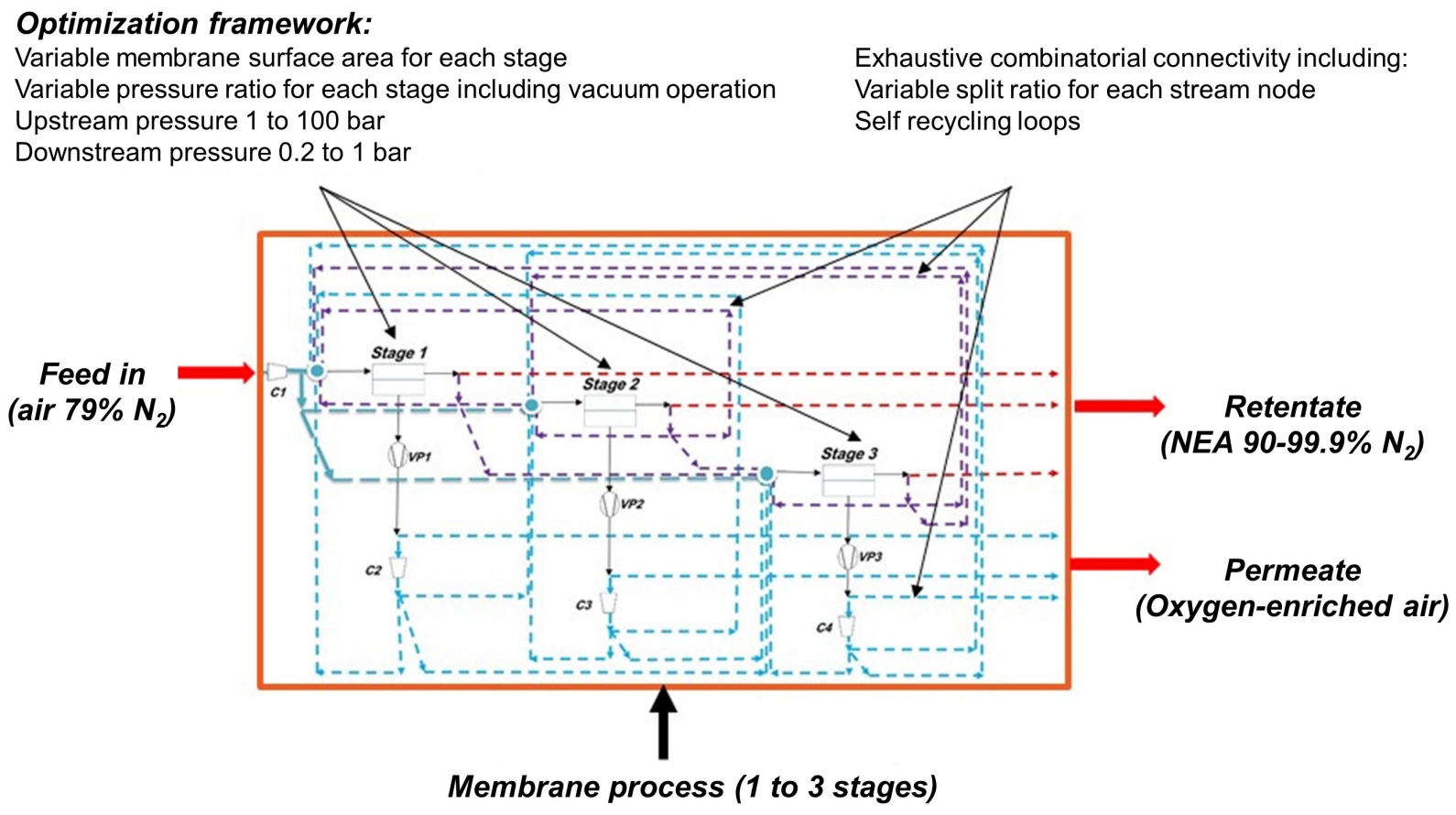

Figure 1: Overall process synthesis framework used for this study. A membrane separation process including up to 3 stages with compressors and/or vacuum pumps and multiple connection possibilities including recycling loops is applied to nitrogen production from air with four different target purities. The different configuration possibilities and operating variables are taken into account in order to achieve the lowest production cost (i.e. objective function, detailed in Tables 1 and 2).

The program makes use of a rigorous set of equations for membrane module simulation, extendable to multi-component mixtures [14]. All the possibilities of connections are explored for a system with one, two or three stages, including recycling loops from one stage to another or self recycling loops. One specificity of the program, compared to most of the approaches in this domain, is to allow a variable pressure ratio in each stage with vacuum pumping as one possibility. A given range is applied to the operating conditions, in order to take into account technological limitations (typically upstream pressure is limited to 100 bar and vacuum limited to 0.2 bar). Compressors or vacuum pumps are included in the recycling loops when pressure changes exist at the boundaries of the connection. The overall cost function, taken as the objective function, takes into account capital expenses (CAPEX) such as compressors, vacuum pumps, membrane modules and operating costs (OPEX), such as energy requirement, membrane replacement and operation and maintenance cost. The cost function used for NEA production is detailed in Table 1. The detailed mathematical framework and associated optimization strategy can be found in [13]. 
Table 1: Cost equations used to determine product gas separation cost

\begin{tabular}{|c|c|c|}
\hline \multicolumn{3}{|l|}{ Equipment cost } \\
\hline $\mathrm{I}_{\mathrm{m}_{\mathrm{s}}}=\mathrm{A}_{\mathrm{m}_{\mathrm{s}}} \cdot \mathrm{K}_{\mathrm{m}}$ & (1) & Membrane cost \\
\hline $\mathrm{I}_{\mathrm{mf}_{\mathrm{s}}}=\left(\mathrm{A}_{\mathrm{m}_{\mathrm{s}}} / 2000\right)^{0.7} \cdot \mathrm{K}_{\mathrm{mf}} \cdot\left(\mathrm{p}^{\mathrm{up}} / 55\right)^{0.875}$ & $(2)$ & Membrane frame cost \\
\hline $\mathrm{I}_{\mathrm{ccs}_{\mathrm{s}}}=\mathrm{C}_{\mathrm{cc}} \cdot\left(\mathrm{W}_{\mathrm{cp}_{\mathrm{s}}} / 10^{6}\right)^{0.7} \cdot \mathrm{MF}_{\mathrm{cc}} \cdot \mathrm{MDF}_{\mathrm{cc}} \cdot \mathrm{UF}_{2000}$ & $(3)$ & Stage compressor cost \\
\hline $\mathrm{I}_{\mathrm{cc}_{\mathrm{f}}}=\mathrm{C}_{\mathrm{cc}} \cdot\left(\mathrm{W}_{\mathrm{cp}_{\mathrm{f}}} / 10^{6}\right)^{0.7} \cdot \mathrm{MF}_{\mathrm{cc}} \cdot \mathrm{MDF}_{\mathrm{cc}} \cdot \mathrm{UF}_{2000}$ & $(4)$ & Feed compressor cost \\
\hline $\mathrm{I}_{\mathrm{vp}_{\mathrm{s}}}=\mathrm{C}_{\mathrm{vp}} \cdot\left(\mathrm{W}_{\mathrm{vp}_{\mathrm{s}}} / 10^{3}\right)$ & $(5)$ & Vacuum pump cost \\
\hline \multicolumn{3}{|l|}{ Capital expenditures } \\
\hline $\mathrm{CAPEX}=\left(\mathrm{I}_{\mathrm{cc}_{\mathrm{f}}}+\sum_{\mathrm{s} \in \mathcal{S}}\left(\mathrm{I}_{\mathrm{m}_{\mathrm{s}}}+\mathrm{I}_{\mathrm{mf}_{\mathrm{s}}}+\mathrm{I}_{\mathrm{cc}_{\mathrm{s}}}+\mathrm{I}_{\mathrm{vp}_{\mathrm{s}}}\right)\right) \cdot \mathrm{ICF}$ & (6) & Total capital cost \\
\hline \multicolumn{3}{|l|}{ Operational expenditures } \\
\hline $\mathrm{C}_{\mathrm{O} \& \mathrm{M}}=\sum_{\mathrm{s} \in \mathcal{S}} \mathrm{A}_{\mathrm{m}_{\mathrm{s}}} \cdot \nu \cdot \mathrm{K}_{\mathrm{mr}}+0.03 \cdot \mathrm{CAPEX}$ & $(7)$ & Operation and maintenance cost \\
\hline $\mathrm{C}_{\mathrm{en}}=\mathrm{t}_{\mathrm{op}} \cdot \mathrm{W}_{\mathrm{tot}} \cdot \mathrm{K}_{\mathrm{el}}$ & $(8)$ & Energy cost \\
\hline $\mathrm{OPEX}=\mathrm{C}_{\mathrm{en}}+\mathrm{C}_{\mathrm{O \& M}}$ & $(9)$ & Total operational expeditures \\
\hline \multicolumn{3}{|l|}{ Annual and specific separation costs } \\
\hline $\mathrm{C}_{\mathrm{cap}}=\mathrm{CAPEX} \cdot \mathrm{a}$ & $(10)$ & Annual capital costs \\
\hline $\mathrm{C}_{\mathrm{tot}}=\mathrm{C}_{\mathrm{cap}}+\mathrm{OPEX}$ & $(11)$ & Total annual costs \\
\hline $\mathrm{M}_{\mathrm{N}_{2} \text { per year }}=\mathrm{F}^{\text {Ret }} \cdot \mathrm{X}_{\mathrm{N}_{2}}^{\mathrm{Ret}} \cdot \mathrm{M}_{\mathrm{N}_{2}} \cdot 10^{-6} \cdot 3600 \cdot \mathrm{t}_{\mathrm{op}}$ & $(12)$ & Annual separated $\mathrm{N}_{2}$ \\
\hline $\mathrm{SC}_{\mathrm{N}_{2}}=\mathrm{C}_{\text {tot }} / \mathrm{M}_{\mathrm{N}_{2} \text { per year }}$ & $(13)$ & Specific $\mathrm{N}_{2}$ separation cost \\
\hline
\end{tabular}


Table 2: Cost parameters used in Table 1

\begin{tabular}{llr}
\hline Capital cost parameters & \\
\hline $\mathrm{C}_{\mathrm{cc}}$ & $1 \times 10^{6}$ & $\mathrm{EUR}_{2000}$ \\
$\mathrm{C}_{\mathrm{vp}}$ & 1500 & $\mathrm{EUR} / \mathrm{kW}$ \\
$\mathrm{K}_{\mathrm{m}}$ & 40 & $\mathrm{EUR} / \mathrm{m}^{2}$ \\
$\mathrm{~K}_{\mathrm{mf}}$ & $286 \times 10^{3}$ & $\mathrm{EUR}$ \\
$\mathrm{MDF}_{\mathrm{cc}}$ & 2.72 & - \\
$\mathrm{MF}_{\mathrm{cc}}$ & 1.4 & - \\
$\mathrm{UF}_{2000}$ & 1.42 & - \\
$\mathrm{ICF}$ & 1.8 & - \\
$\mathrm{T}$ & 308.15 & $\mathrm{~K}$ \\
$\mathrm{R}$ & 8.314 & $\mathrm{JK}^{-1} \mathrm{~mol}^{-1}$ \\
$\eta$ & 0.85 & - \\
$\phi$ & 0.95 & - \\
$\gamma$ & 1.36 & - \\
$\lambda$ & 0.85 & - \\
\hline Annual cost parameters & & - \\
\hline$\nu$ & 0.2 & $\mathrm{EUR} / \mathrm{m}^{2}$ \\
$\mathrm{~K}_{\mathrm{mr}}$ & 25 & $\mathrm{~h} / \mathrm{year}$ \\
$\mathrm{t}_{\mathrm{op}}$ & 8322 & - \\
$\mathrm{K}_{\mathrm{el}}$ & 0.044 & $\mathrm{EUR} / \mathrm{kWh}$ \\
$\mathrm{a}$ & 0.0854 & $\mathrm{~g} / \mathrm{mol}$ \\
$\mathrm{M}_{\mathrm{N}_{2}}$ & 28.01 & \\
\hline
\end{tabular}

Three different strategies have been used in the study:

- As a first step, membrane separation characteristics are fixed (i.e. membrane oxygen and nitrogen permeance), and the optimal process design and operating conditions is obtained for one, two and three membrane stages, for the four levels of target nitrogen purity (90, 95, 99 and 99.9\%). Benchmark gas permeances for commercially available membranes are used.

- As a second step, the membrane characteristics are allowed to vary within a defined domain, limited by trade-off performances represented by Robeson's upper bound relationship and a single set of membrane permeances is allowed. As a consequence, the solutions obtained in that case necessarily make use of the same, optimal membrane, for all the stages of the system.

- As a final step, membrane permeances for each individual stage are allowed to vary within the same domain as in the previous step. This allows a different optimal membrane to be selected for each stage, when a multistage solution is investigated.

Nitrogen ranks among the top ten chemicals in terms of production capacity (ca 100 million tons per year), with a large portfolio of applications (inerting in chemical industries, food protection, steel manufacturing, light bulbs, cryopreservation) [14]. Production technologies systematically use air as a feedstock (i.e. 0.79 volume fraction nitrogen content). Depending on the nitrogen purity and unit capacity, cryogeny, adsorption based processes (PSA, Pressure Swing Adsorption) or membranes are used [15]. Membrane separations for 
NEA (Nitrogen Enriched Air) production correspond to the most recent production technology and compete with cryogeny and PSA when a moderate purity (typically below 99) and moderate capacity are required [16]. As already explained, Nitrogen production from air is today the biggest market of membrane gas separation processes, with more than 100 000 units installed through the world [4]. From a membrane material point of view, dense polymers are exclusively used [17]. Oxygen, water and carbon dioxide are faster permeants than nitrogen into polymers. As a consequence, NEA is recovered dry and purified on the retentate (i.e. high pressure) outlet of the membrane modules. Different polymers have been developed for industrial scale application, with a classical selectivity / productivity trade-off to be tackled. Polysulfone (PSf), Polyimides (PI) and Poly-phenylene-oxide (PPO) dense skin membranes are commercially available [2]. The two major performance characteristics of a given dense skin membrane are the separation performance, expressed through the $\mathrm{O}_{2} / N_{2}$ selectivity $\left(\alpha^{*}\right)$, and the effective membrane productivity, usually expressed in GPU (Gas Permeation Unit). The selectivity / permeability trade-off curve for different polymers for the $\mathrm{O}_{2} / \mathrm{N}_{2}$ gas pair is shown on Figure 2a. It can be noticed that oxygen is systematically faster than nitrogen $(\alpha>1)$. In order to translate the intrinsic polymer permeability into a process productivity variable (i.e. permeance, in GPU), a dense skin of $1 \mu m$ thickness is often assumed [18]. The corresponding graph is shown on Figure $2 \mathrm{~b}(1$ Barrer corresponds to 1 GPU in that case). The current level of performances of two classical commercially available air separation membranes (PSf and PPO), which will be used in this study,is indicated. 


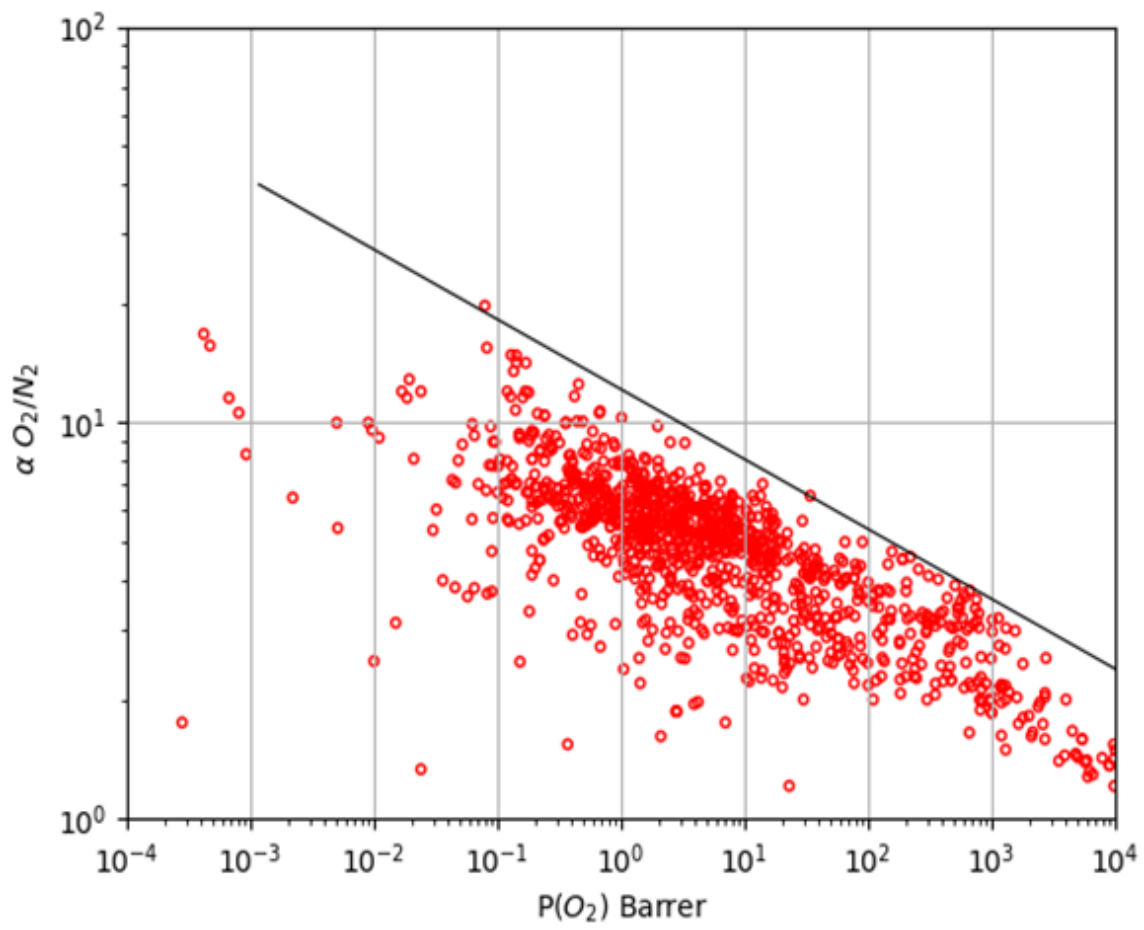

(a) $\mathrm{O}_{2} / N_{2}$ polymeric materials trade-off curve [12]

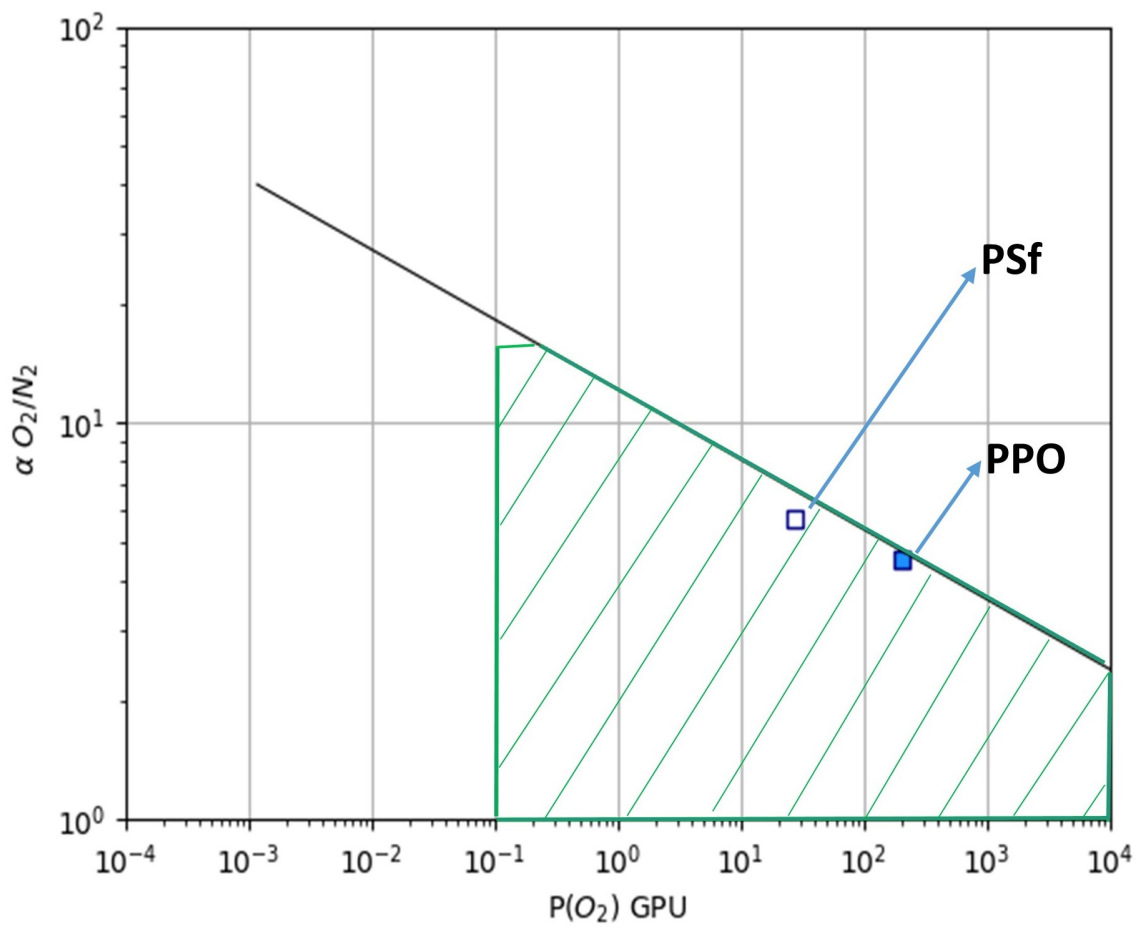

(b) Selectivity / permeance trade-off curve based on a $1 \mu \mathrm{m}$ skin layer thickness and performances of two commercially available membrane materials (PSf and PPO). Dashed area corresponds to the domain used for optimal membrane identification when performances are not fixed

Figure 2 
Besides the membrane material selection question, a process design analysis has also to be performed. The goal is to identify the most effective process structure and operating conditions, which reaches the specifications (nitrogen purity and production capacity) with the lowest cost. Surprisingly, this point is poorly documented in the open literature, despite the important market of nitrogen membrane production units. Figure 3 summarizes three main configurations reported from industrial practice, which correspond to increasing levels of nitrogen purity [16]. An increasing number of membrane stages is needed when increasing the target nitrogen purity. The maximum number of stages is however limited to three, because of the strong impact of multiple compressors in the overall cost $[1,2,4]$. The increasing complexity of the process when a larger purity is aimed is noticeable (multiple stages with recycling loops).

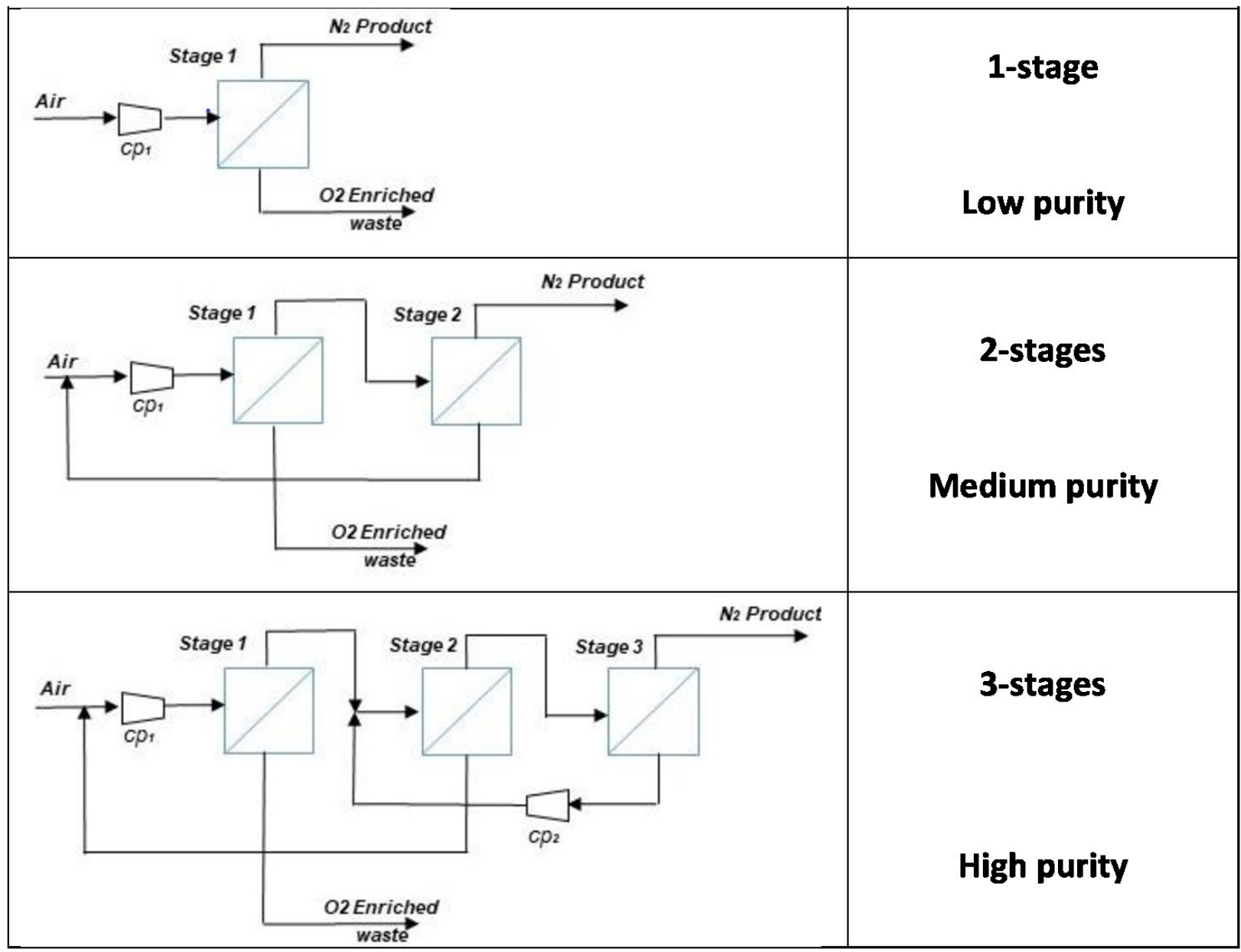

Figure 3: Membrane process configurations for three different levels of nitrogen purity, adapted from [16]

The process configurations reported on Figure 3 correspond to the current state of the art of the most effective structures obtained with commercially available polymeric air separation membrane materials. Nevertheless, due to the very large nitrogen market, tremendous efforts have been made the last decades in order to push the limits of polymer performances. It is thus important to explore the impact of high performances membrane materials both in 
terms of nitrogen production costs and optimal process configurations.

\subsection{NEA production: high performance materials}

A series of high performance membrane materials covering a broad range of selectivity / permeability trade-off is detailed in Table 3. The different possibilities can be expressed through a generic trade-off equation, such as suggested by [12]. For the specific oxygen / nitrogen pair gas, the trade-off limit can be expressed as:

$$
P_{O_{2}}=k \alpha^{n}
$$

where $k=1396000$ Barrer and $n=-5.666$.

This generic equation will be used to evaluate the interest of different high performance materials in the process synthesis study reported hereafter.

Table 3: Examples of advanced membrane materials (not commercially available today), close to the Robeson trade-off limit, for air separation applications (from [12]).

\begin{tabular}{|c|c|c|}
\hline Polymer & $\begin{array}{c}\text { Permeability } \\
O_{2} \text { (Barrer) }\end{array}$ & $\begin{array}{c}\alpha \\
O_{2} / N_{2}\end{array}$ \\
\hline \hline Polyimide (BPDA-ODA) & 0.079 & 19.8 \\
\hline Polyimide (BTDA-ODA) & 0.170 & 14.2 \\
\hline Polyetherimide & 0.90 & 11.2 \\
\hline Polypyrrolone (6FDA/PMDA(25/75)-TAB) & 1.01 & 10.03 \\
\hline PPO sulfonated (32.9\%) and brominated (60 \%) & 12.6 & 7.4 \\
\hline PPO sulfonated (20.2 \%) and brominated (60 \%) & 14.0 & 7.0 \\
\hline Polyimide (BADBSBF-BTDA) & 18.0 & 9.0 \\
\hline Poly[1-phenyl-2-p-(trimethylsilyl)phenylacetylene] & 1550 & 2.98 \\
\hline PIM-1 & 370 & 4.0 \\
\hline PIM-7 & 190 & 4.5 \\
\hline
\end{tabular}

\section{Results and discussion}

\subsection{Nitrogen production by commercially available membrane materials}

In a first step, the minimal nitrogen production cost with current commercial membrane materials is explored. Two different membranes, summarized in Table 4, have been selected and the corresponding minimal production cost and optimal process configuration were evaluated. The two materials detailed in Table 4 correspond to two major families of polymers used for air separation applications. Polysulfone shows an increased selectivity, at the expense of a lower permeance. PPO shows the highest oxygen permeance, with a slightly lower selectivity. The objective of this first part of the study is to define the reference production 
costs and process configurations for these two membranes. The sensitivity of selectivity versus permeance, in terms of production cost and possible process configuration differences is also of interest.

Table 4: Characteristics of the two commercially available membranes used for NEA production in this work

\begin{tabular}{|c|c|c|c|c|}
\hline Polymer & $\begin{array}{c}O_{2} \text { permeance } \\
(\mathrm{GPU})\end{array}$ & $\begin{array}{c}N_{2} \text { permeance } \\
(\mathrm{GPU})\end{array}$ & $\begin{array}{c}\alpha O_{2} / N_{2} \\
(-)\end{array}$ & Reference \\
\hline \hline Polysulfone (PSF) ${ }^{1}$ & 27 & 4.7 & 5.7 & {$[19]$} \\
\hline Polyphenyleneoxide (PPO) $)^{2}$ & 200 & 44 & 4.5 & {$[20]$} \\
\hline
\end{tabular}

The results obtained for PSF and PPO membranes are summarized figures 4 and 5 respectively. 


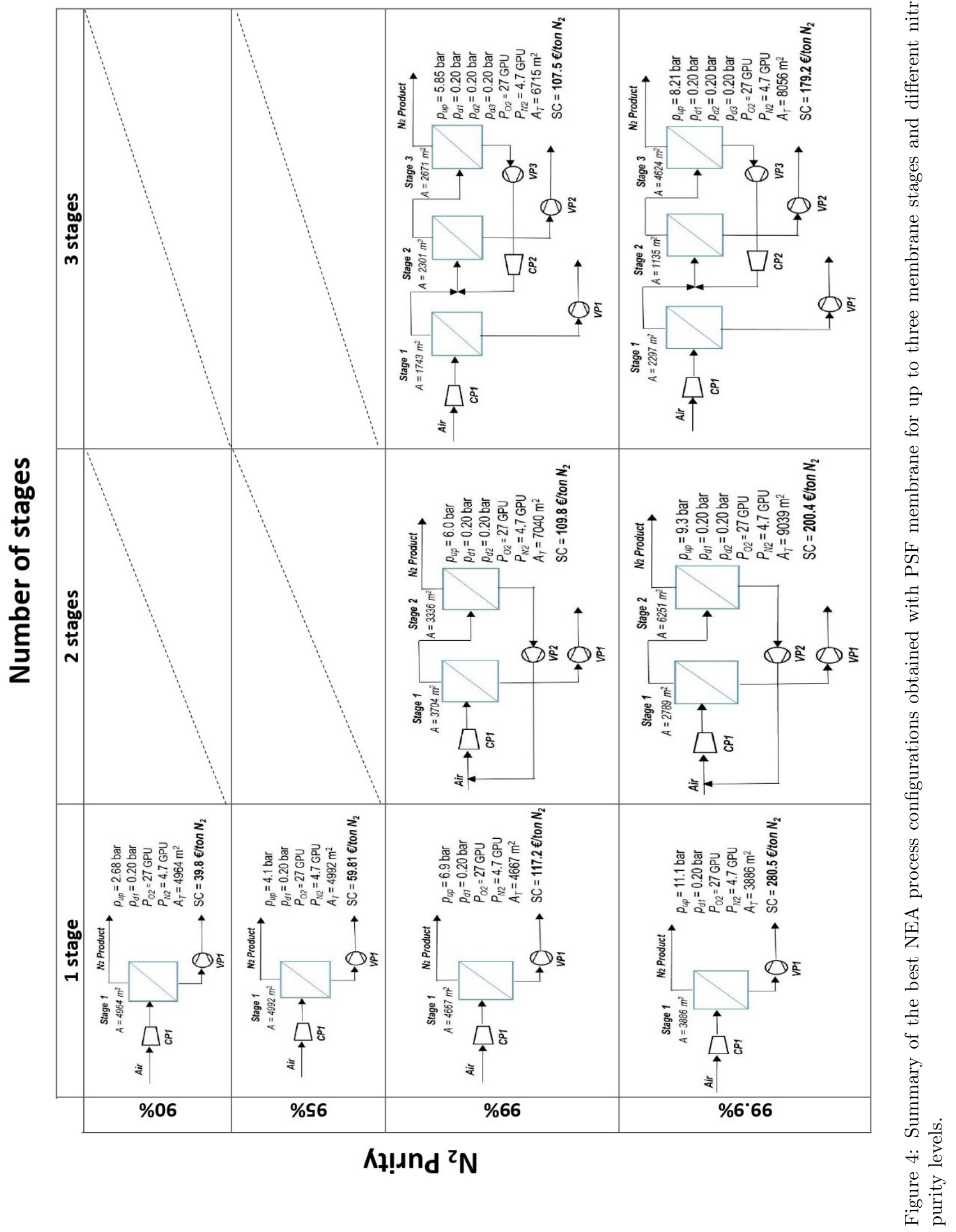




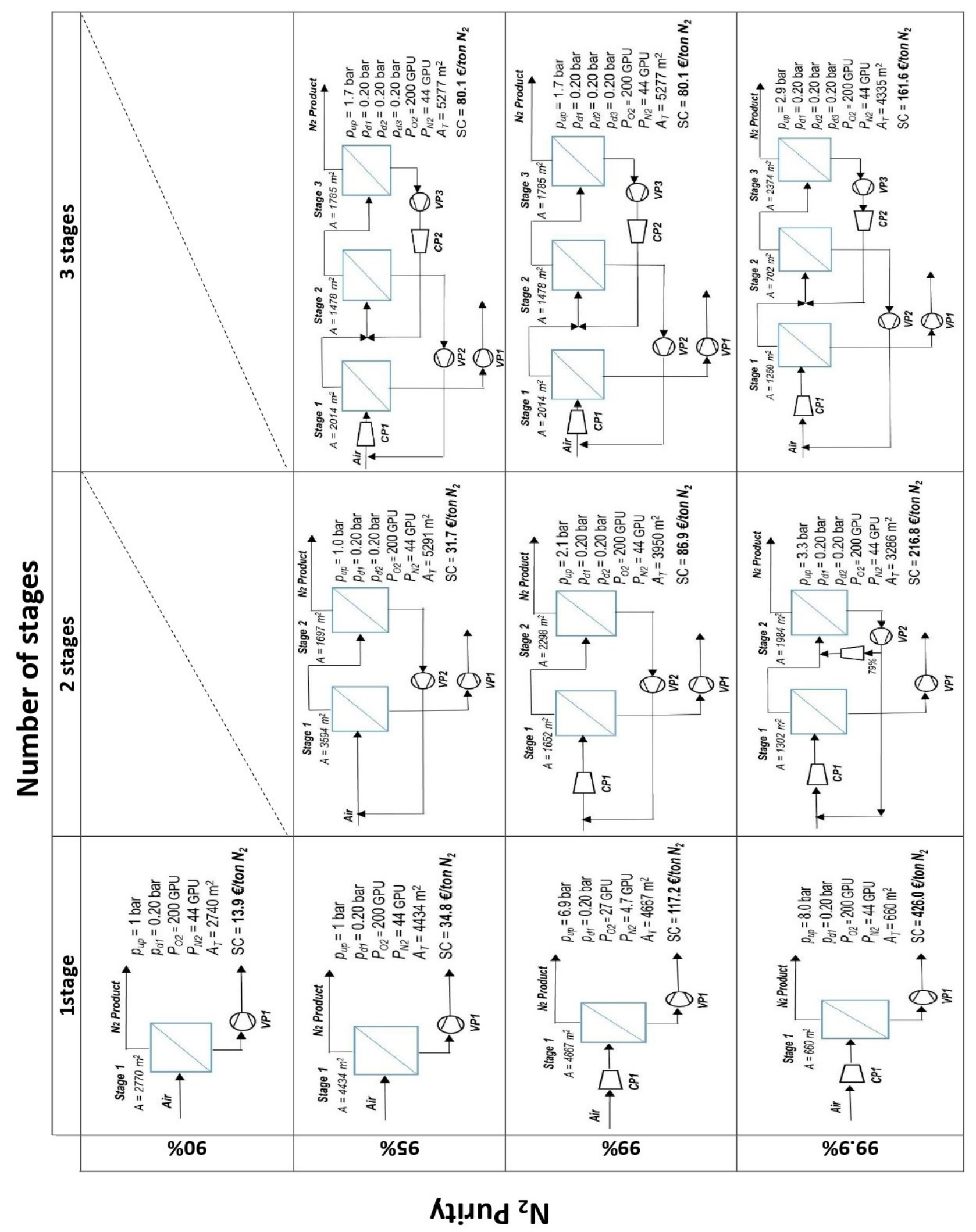

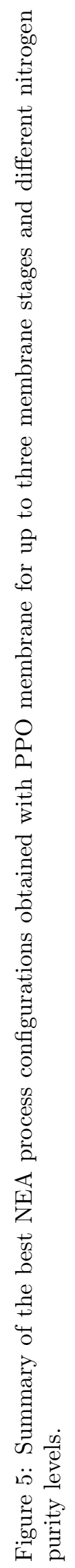


Generally speaking, figures 4 and 5 confirm general statements and guidelines of membrane gas separation processes presented figure 3:

- An increased target purity increases the nitrogen production cost through a non linear, quasi exponential dependence

- An increased nitrogen purity translates into an increasing number of stages and increasing process complexity (e.g. multiple recycling loops, combined compression and vacuum operation...).

A single stage process with no recycling loop systematically offers the best performances for 90 percent purity. Interestingly, no solution with 2 or 3 stages can be obtained by the computer program for this purity level. A series of 2 or 3 modules is generated, without recycling loop, without any recompression step; this is then equivalent to a single, segmented module. A two stage configuration with recycling loop is the best process for moderate $(95$ percent) nitrogen purity. Three stages, including two recycling loops, are needed for larger purity levels (99 and 99.9 percent). It is likely that nitrogen production cost is not competitive at this purity level. The competitive window for nitrogen production by membranes is effectively often mentioned to range from 90 to 99 percent [16].

The general structures obtained through the process synthesis study perfectly fit the structures reported up to now (figure 3). The number of stages for the different purity levels, the number and location of the recycling loops for multistage processes are exactly the same as the one detailed in figure 3 . This point is remarkable and provides a good proof of the efficiency and relevance of the simulation/optimization program when applied to existing membrane materials. Moreover, a nitrogen production cost around 30 Euros per ton is obtained for a 95 percent purity, which matches the cost reported in a recent study [21] Furthermore, besides the confirmation of the three different process flow-sheets detailed in Figures 4 and 5, the optimal structures and operating conditions obtained with commercial PSF and PPO membranes lead to additional insights, which are of interest:

- Vacuum operation is of major interest in order to generate the lowest production cost. This option is rarely taken into account by membrane process synthesis softwares. This operation possibility is included in our tailor made program and seems to be important for cost minimization. It has to be stressed however that vacuum operation is most often discarded for industrial units, because of the large footprint of vacuum pumps, low energy efficiency and problems generated by leaks. Vacuum operation in membrane gas separations is effectively limited to VOC recovery, oxygen enriched air or carbon capture [4]. These serious limitations have to be taken into account for NEA production. The optimal flow-sheets reported in Figures 4 and 5 suggest however that the use of vacuum in place of or complementary to feed compression should be investigated. Feed compression is operated only for high purity levels, when too large membrane surface areas are needed. Vacuum pumping seems however to offer a very useful solution when membrane surface area and energy requirement have to be balanced.

- Nitrogen production costs with PPO are systematically lower than with PSF. This suggests that a larger permeance such as offered by PPO is more interesting than a 
higher selectivity (offered by PSf).

The reference case obtained through this first process synthesis study confirms the rules and guidelines reported for nitrogen production by membranes. The impact of novel, high performance materials, such as those detailed in Table 3 and corresponding to trade-off limits, on these guidelines and conclusion are analyzed in the next section.

\subsection{Nitrogen production by high performance membrane materials}

In the second part of this study, the minimal nitrogen production cost with high performances membrane materials, within the trade-off limits, is explored. In that case, membrane performances (i.e. oxygen and nitrogen permeances) are not fixed (such as in the previous step) but these two variables are free within the trade-off limits shown on Figure $2 b$ (dashed area). Two different strategies have been compared:

- Membrane permeances are allowed to vary within the trade-off limits but the same membrane is used for all stages. One set of permeances is considered as in the previous section, but instead of being input values, the optimal pair of gas permeances are determined along with process configuration and operation parameters for each level of nitrogen purity by the optimization program.

- Membrane performances are allowed to vary within the trade-off limits but a different membrane can be selected for each stage. A set of optimal membrane permeances will be determined for each stage and nitrogen purity level. To our knowledge, this possibility has never been explored up to now for NEA production. The results of the optimization (process synthesis) are expected to generate useful guidelines for membrane material development: is it better to push selectivity or permeance in order to decrease NEA production cost? Is it interesting to combine different membranes in a multistaged unit, in order to achieve lower production costs?

The results of the two strategies (optimal membrane for all stages and optimal membrane for each stage) for NEA production study for the four levels of nitrogen purity and for 1 , 2 and 3 stages units are detailed in the appendix A.10 and A.11. The optimal selectivity

/ permeance for fixed and variable strategies are summarized Figure 6. Except for the 99.9 percent purity case, most optimal membrane performances are very close together. An increased permeance is favored, at the expense of a slight decrease in selectivity. Surprisingly, the variable permeability option (figure $6 \mathrm{~b}$ ) does not offer interesting performances. The different membrane performances for the optimal membranes per stage case are indeed very close and located in the same place as the optimal membrane for all stages case. This result is somewhat unexpected and it is of interest for NEA production.

The optimal flowsheets and operating conditions are summarized in Figure 7 for both strategies. 


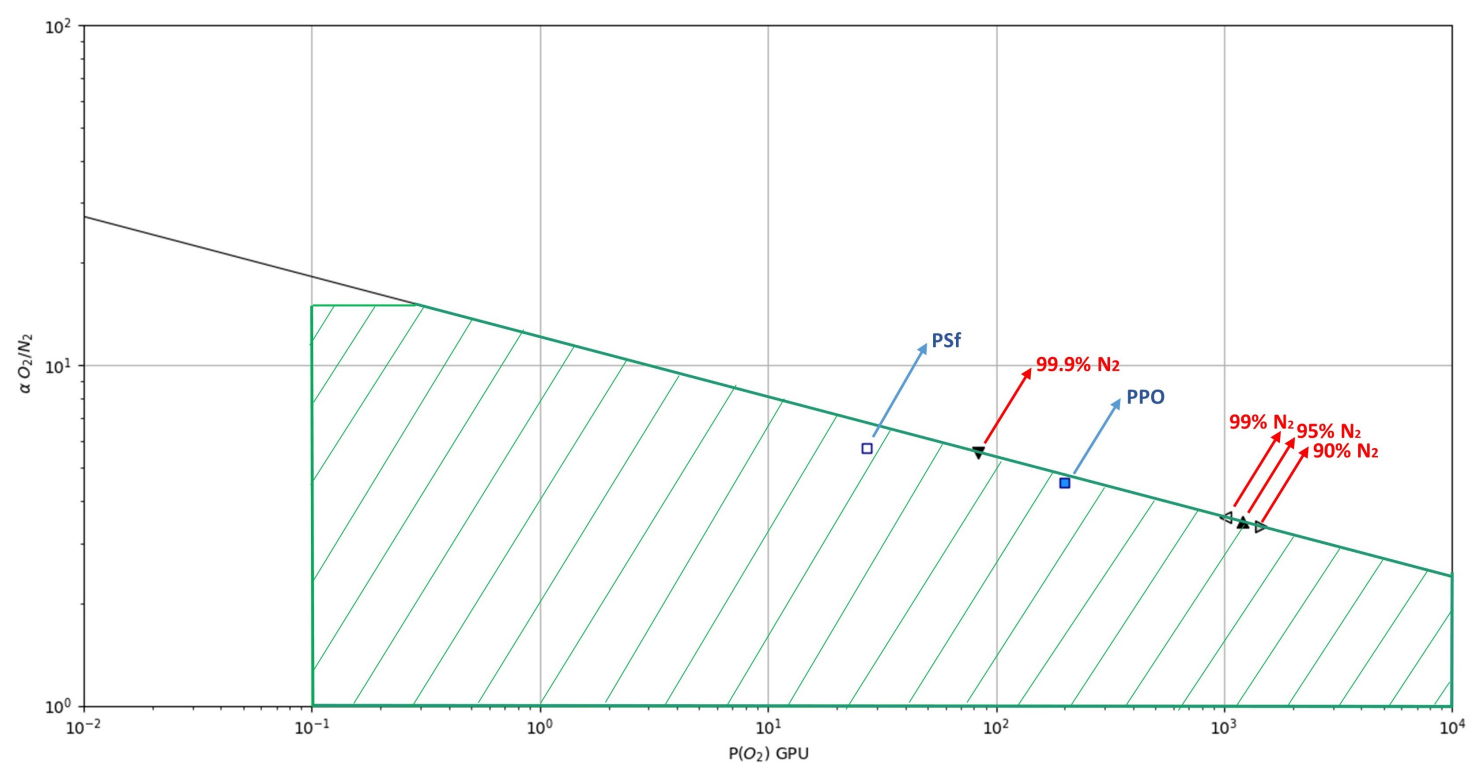

(a) Optimal membrane performances for the different nitrogen purity levels when the same membrane is used in all stages.

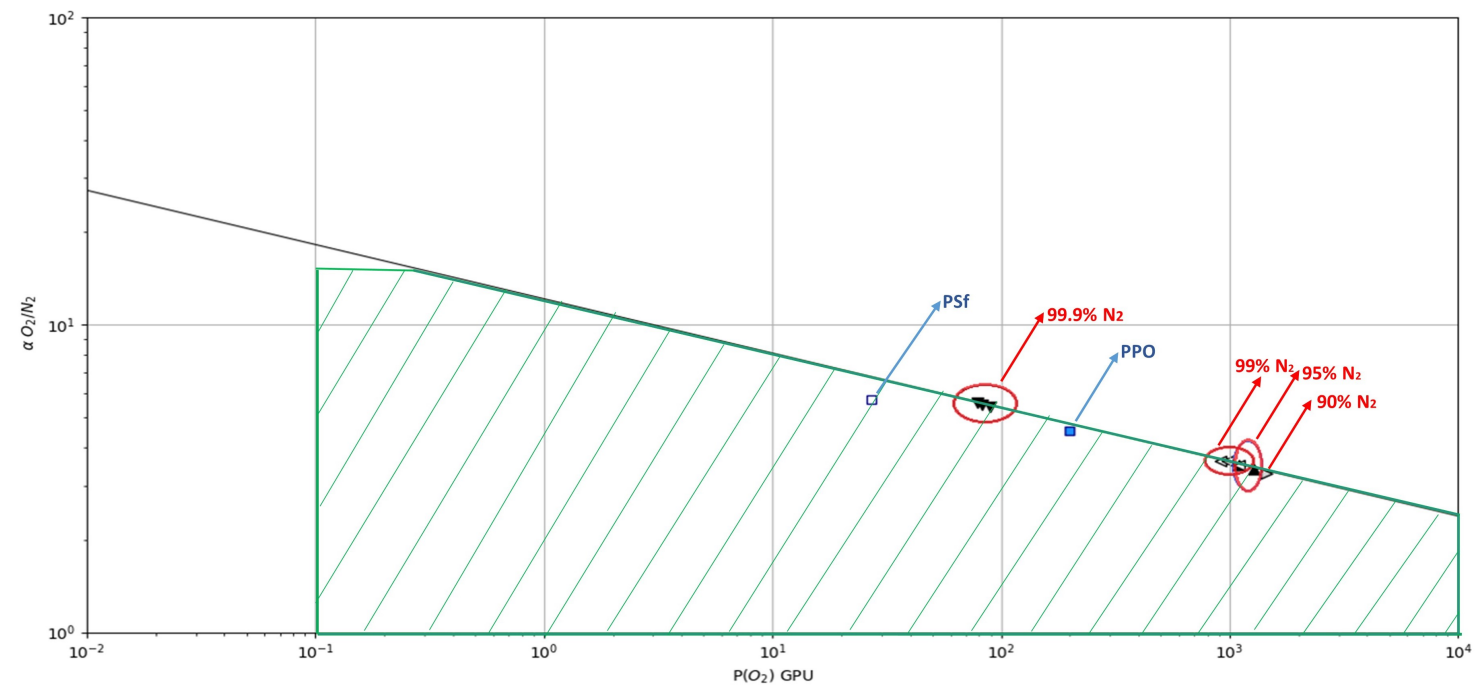

(b) Optimal membrane performances for the different nitrogen purity levels when a different membrane is used in each stage. PSF and PPO membranes are included for reference.

Figure 6 


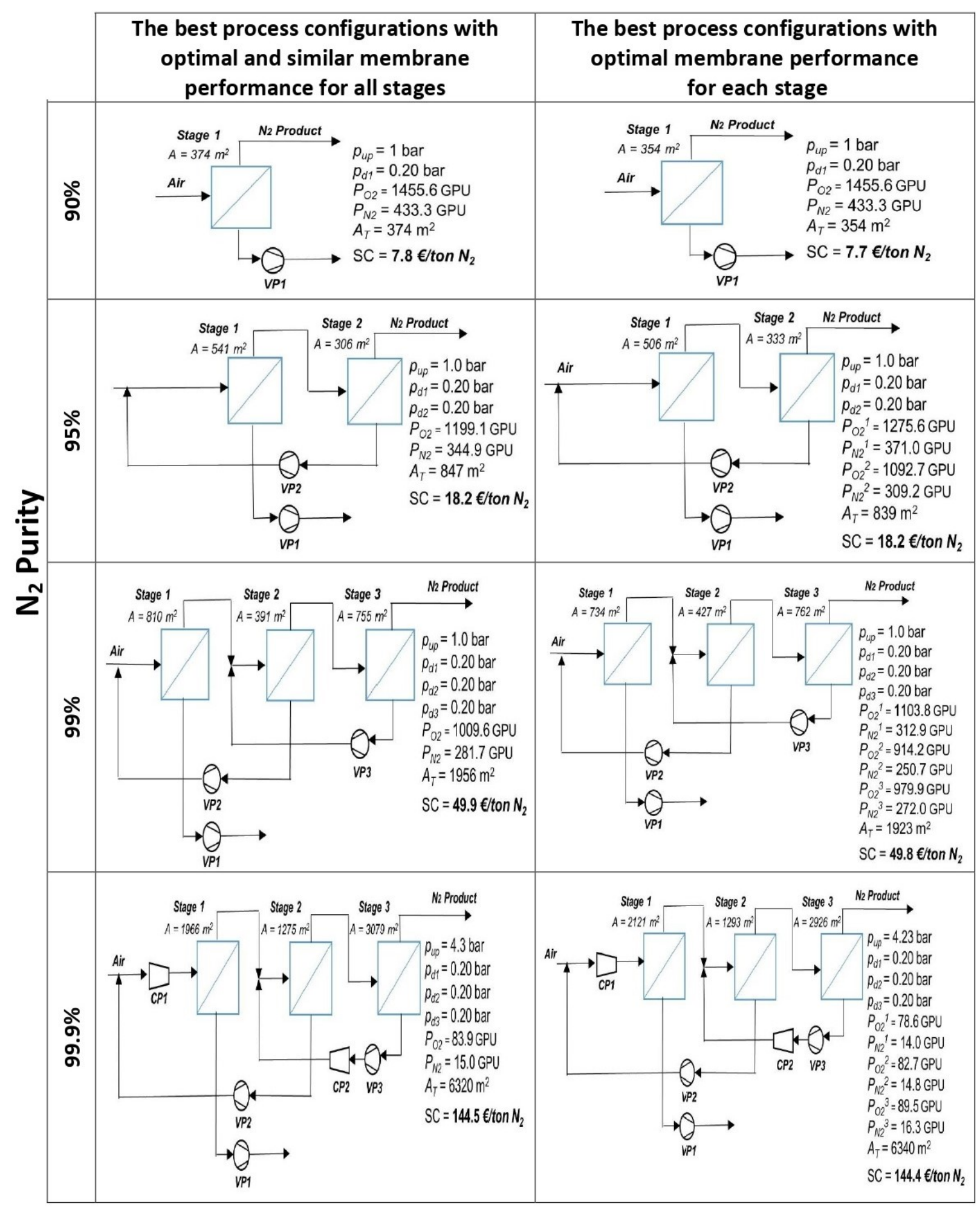

Figure 7: Overall best process configurations with up to three membrane stages at different nitrogen purity levels including optimal membrane permeances when the same membrane is used in all stages (left) and when a different membrane is used in each stage (right). 
From a production cost point of view, the high performance materials generate a significant decrease. A comparison between Figure 4-5 and Figure 7 shows the the impact of improved membrane materials for the minimization of NEA production costs. The cost difference between having an overall optimal membrane or having different optimal membranes for each stage is negligible. This clearly results from the fact that the latter approach ends up to similar membrane performances than those generated by just considering one optimal membrane performance for all stages.

Since the results presented above highligth the interest of permeance over selectivity for NEA production, it is tempting to explore the incidence of thinner layers (i.e. larger permeance). Thin dense layers down to $50 \mathrm{~nm}$ are effectively achievable for some gas separation membranes [3]. A $0.1 \mu \mathrm{m}$ thickness could thus be possibly obtained with the trade-off materials listed in Table 3. This point is analysed in the next section.

\subsection{Nitrogen production by high performance membrane materials and ultra thin dense layer membranes}

An optimization study of trade-off membrane materials showing a ten fold increase in permeance has been undertaken. This new case study corresponds to $0.1 \mu \mathrm{m}$ thick layer membranes, in place of the standard $1 \mu \mathrm{m}$ assumption taken in the previous sections. The best configurations, operating conditions and membrane performances for the four nitrogen purity levels are summarized figure 8.

The optimal membrane perfomances for the one membrane for all stages and one membrane for each stage strategies are shown on the trade off curves presented figure 9 . 


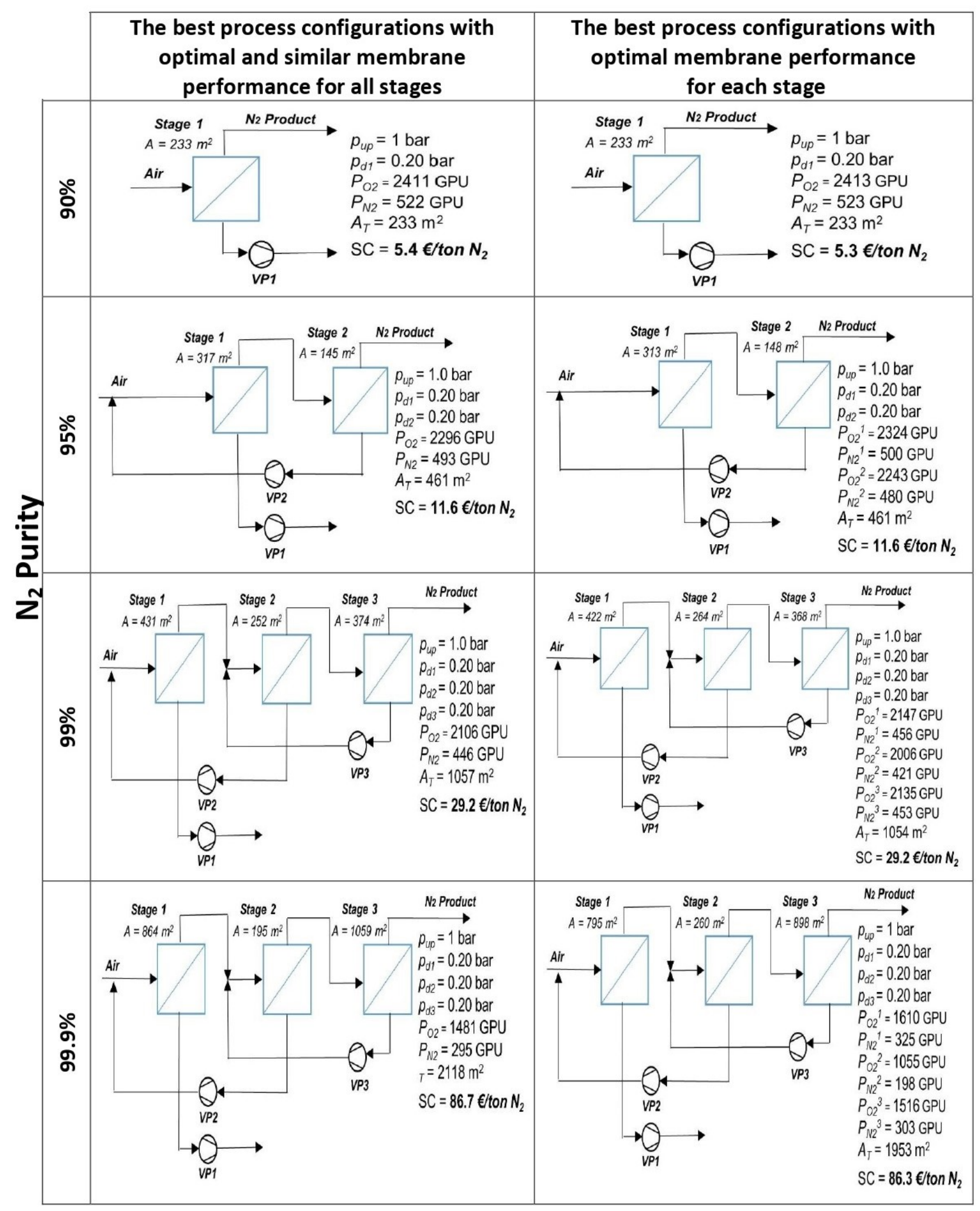

Figure 8: Overall best process configurations with up to three membrane stages at different nitrogen purity levels including optimal membrane permeances when the same membrane is used in all stages (left) and when a different membrane is used in each stage (right). Membrane thickness used to calculate membrane permeance from permeability values is taken as $0.1 \mu \mathrm{m}$. 


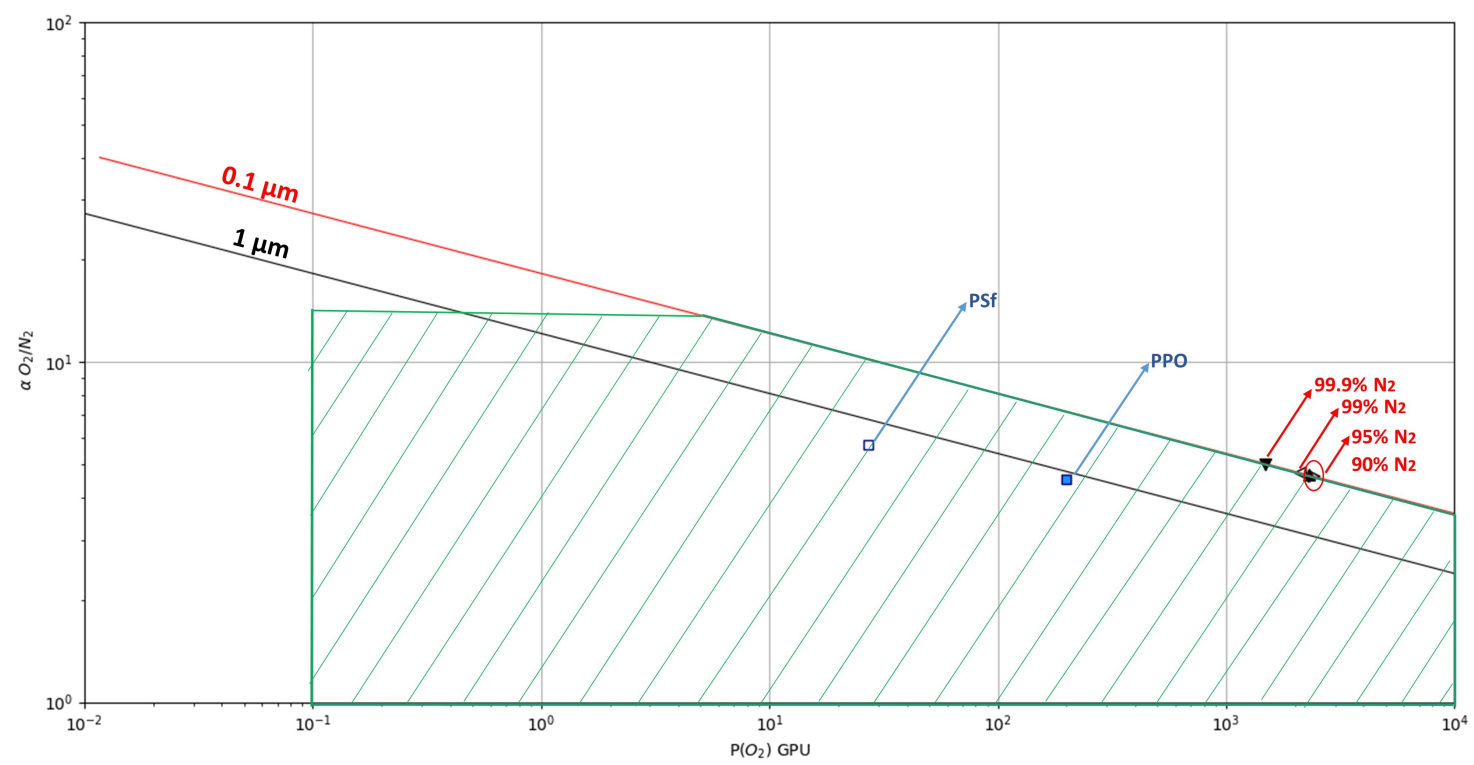

(a) Optimal membrane performances for the different nitrogen purity levels when the same membrane is used in all stages

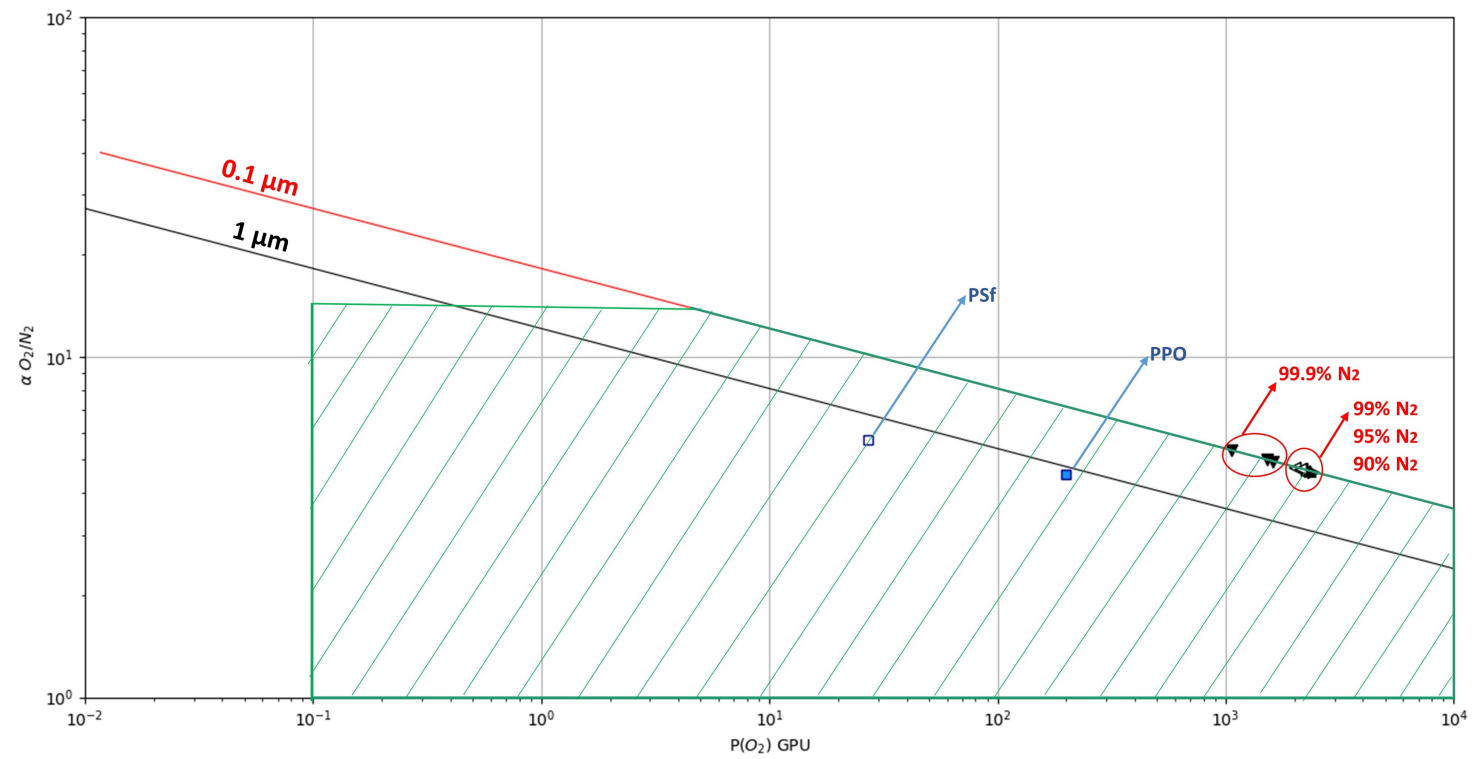

(b) Optimal membrane performances for the different nitrogen purity levels when a different membrane is used in each stage. PSF and PPO membranes are included for reference.

Figure 9

The two strategies show, again, very close results. This confirms that for NEA production, the association of different membranes into multistage units is of low interest. A very narrow domain is obtained for optimal membrane performances for the different nitrogen purity levels. This result is surprising and also interesting because it suggests that a single optimal membrane development could possibly fit the requirements for a broad range of nitrogen purities. In terms of selectivity / permeance trade-off, the optimal membrane characteristics clearly shift towards larger permeances, without large increase in selectivity. This unexpected 
result corresponds to a generic guideline for membrane materials development for NEA production: permeance has to be favored. The performances of recently reported materials such as PIM, with ultra-high permeabilities [10], are of major interest in that perspective. It is worth to note that with high permeance membranes, the process configurations remain unchanged for each purity level, but the specific cost is largely decreased (typically around 40 percent). This highlights the potential of thin, highly permeable membrane materials for nitrogen production.

\subsection{Synopsis}

In the last part of this study, the different case studies are summarized in Table 5, in order to enable an overview of the key results. The optimal conditions for the four purity levels are presented for the current membrane materials (represented by PPO results), trade-off materials and ultra-high permeance materials (limited to the one optimal membrane for all stages case, the differences with the optimal membrane for each stage case being very small).

Table 5: Summary of the best process configurations for NEA production with commercial membrane (PPO) and trade-off membrane materials with uniform permeability and 1 and $0.1 \mu m$ membrane layer thickness.

\begin{tabular}{|c|c|c|c|c|c|c|c|c|}
\hline & $N_{2}$ purity & $\operatorname{Cost}\left(E U R / \operatorname{ton} N_{2}\right)$ & Number of stages & $\alpha$ & $P_{O_{2}}(\mathrm{GPU})$ & $V_{p} / C_{p}$ & $\theta$ & $\operatorname{Energy}\left(k W h / N m^{3}\right)$ \\
\hline \multirow{4}{*}{$\begin{array}{c}\text { Commercial membrane } \\
\qquad(\mathrm{PPO})\end{array}$} & $90 \%$ & 13.9 & 1 & 4.54 & 200 & $V_{p}$ & 0.44 & 0.07 \\
\hline & $95 \%$ & 31.7 & 2 & 4.54 & 200 & $V_{p}$ & 0.57 & 0.16 \\
\hline & $99 \%$ & 80.1 & 3 & 4.54 & 200 & $V_{p} \& C_{p}$ & 0.59 & 0.36 \\
\hline & $99.9 \%$ & 161.6 & 3 & 4.54 & 200 & $V_{p} \& C_{p}$ & 0.67 & 0.79 \\
\hline \multirow{4}{*}{$\begin{array}{c}\text { Optimal membrane performance } \\
\text { with } 1 \mu m \text { dense layer } \\
\text { for all stages }\end{array}$} & $90 \%$ & 7.8 & 1 & 3.4 & 1455.6 & $V_{p}$ & 0.54 & 0.1 \\
\hline & $95 \%$ & 18.2 & 2 & 3.5 & 1199.1 & $V_{p}$ & 0.64 & 0.22 \\
\hline & $99 \%$ & 49.9 & 3 & 3.6 & 1009.6 & $V_{p}$ & 0.76 & 0.56 \\
\hline & $99.9 \%$ & 144.5 & 3 & 5.6 & 83.9 & $V_{p} \& C_{p}$ & 0.57 & 0.59 \\
\hline \multirow{4}{*}{$\begin{array}{c}\text { Optimal membrane performance } \\
\text { with } 0.1 \mu m \text { dense layer } \\
\text { for all stages }\end{array}$} & $90 \%$ & 5.4 & 1 & 4.6 & 2411 & $V_{p}$ & 0.45 & 0.07 \\
\hline & $95 \%$ & 11.6 & 2 & 4.6 & 2296 & $V_{p}$ & 0.57 & 0.15 \\
\hline & $99 \%$ & 29.2 & 3 & 4.7 & 2106 & $V_{p}$ & 0.68 & 0.37 \\
\hline & $99.9 \%$ & 86.7 & 3 & 5 & 1481 & $V_{p}$ & 0.85 & 0.98 \\
\hline
\end{tabular}

The overall set of results which are detailed in Table 5 can be summarized as follows:

- A higher nitrogen purity logically generates higher (non linear) production costs. This logical statement applies to both the current commercially available membranes and advanced prospective materials.

- Trade-off membrane materials offer promising performances in terms of production cost, with a two to three fold decrease compared to the current production cost. It is important to note that the average cost of 30 Euros per ton, obtained with commercial PPO gas separation membranes for 95 percent purity, is in excellent agreement with a recent study [21].

- A single stage process is the most economical for the lowest purity level $\left(90 \% N_{2}\right)$, whatever the membrane type. Similarly, two and three stages processes with recycling loops offer better performances for higher nitrogen purity specifications, independently of the membrane characteristics. This shows the robustness of the process flowsheets, generated through engineering studies in the 80's. The three types of configurations, 
selected as target nitrogen purity only (Figure 3) for decades, are indeed confirmed throughout the different case studies explored in this paper.

- In contrast to current practice, the optimal configurations obtained with high performance membrane materials make use of vacuum operation. Except for the high purity target, compression is not the best retained technology for the optimal configuration. This result shows the interest to combine materials and engineering for process design studies, and also the interest to systematically explore the vacuum option in membrane process synthesis studies. It has to be stressed however that vacuum operation is often rejected for industrial applications due to the drawbacks of vacuum pumps (risk of leaks, large footprint, low energy efficiency, higher capital costs). The optimal results shown on figures 7 and 8 thus address a key question in terms of process selection.

- The overall stage cut (i.e. ratio of the total permeate over total feed flowrate) ranges between 0.4 and 0.85. This is typical of industrial membrane units [3]. Thus, the fact that air is considered as free for NEA production does not generate very low stage cut values. Generally speaking, a larger stage cut is obtained when nitrogen purity increases, in order to achieve a much intense oxygen removal (oxygen being faster than nitrogen).

- The energy requirement has been also calculated and it is detailed in the last column of Table 5. Interestingly, the overall energy requirement (classically expressed in kWh per unit feed flowrate [1]) is comparable to previously reported data for NEA production (typically 0.26 to $0.45 \mathrm{kWh}$ per standard cubic meter nitrogen at 98 to 99 percent [1]). Energy requirement for the optimal configuration seems to depend on nitrogen purity only, with a ten fold increase from 90 to 99.9 percent.

- One of the most striking and unexpected result of the study concerns however the optimal membrane performances. First, a moderate selectivity is systematically obtained as the optimal one, whatever the nitrogen purity level. This point is counterintuitive. It is often stated that for high purity, a larger selectivity helps. The subtle interplay between permeance (surface area) and selectivity (separation performances) in multistage configurations including recycling loops suggests however, according to the results shown in figures 7 and 8 that a moderate selectivity associated to a trade-off permeance (i.e a much larger permeance compared to commercial membranes) is the best solution. To some extent, this conclusion is of great interest for the recent generation of high permeability polymers (TRP, PIM, superglassy) [9-11]. Thus, it could be suggested to materials developers to promote permeability increase, rather than trying to develop super selective materials.

- Finally, the most puzzling results comes from the possibility to combine different membrane materials into multistage units. This option is almost unexplored in membrane science and has never been investigated for NEA production. The possibility to combine nitrogen selective and carbon dioxide selective membrane has been shown to offer very attractive performances for carbon capture applications [22]. It might be expected that for NEA production, the same conclusion could be drawn. Our study shows that the situation is completely different. The optimal multistaged processes shown on 
Figure A.11 make use of approximately the same membrane (a moderate selectivity around 3.6 to 4.6, a permeance level at the trade-off limit). It is obvious that this statement does not systematically hold and should be reconsidered from case to case depending on the separation targets and feed mixture. For the set of parameters tested in our NEA study, it seems however that the use of different membranes in a multistage system does not offer attractive improvement possibilities. 


\section{Conclusions and perspectives}

Nitrogen Enriched Air (NEA) is the main application of membrane gas separations today. Nevertheless, few studies have been reported on either process [16, 23, 24] or technoeconomical analyses for this important application $[25,26]$. The situation is quite different for Oxygen Enriched Air (OEA), which has been more extensively investigated [27-30]. Numerous innovative NEA concepts have been explored, including adsorption, hybrid systems or membrane column processes [31-33]. This study intended to achieve a rigorous optimization study of membrane gas separations units with up to three stages.

For the specific case of polymeric membranes, it has been shown that a large progress is achievable for the production cost point of view for low purity NEA (i.e. 90 and 95\%), compared to the existing commercially available membrane materials. A very large cost decrease is also in principle possible for higher purities (i.e. $>95 \%$ ), but the comparison to alternative technologies, such as PSA, is needed in that case.

More specifically, the process synthesis study performed on air separation has shown that :

- Process synthesis converges to the same process configurations as the ones developed by gas producers for a long time (same number of stages and recycling loops as a function of $N_{2}$ purity),

- Trade-off limit membrane materials do not impact the process configuration

- From a membrane materials point of view, a high permeance, combined to a moderate selectivity, offers the best performances, whatever the $N_{2}$ purity target . This result is of great importance for membrane material development because it suggests to promote highly permeable structures rather than very selective materials.

- The possibility to use different membranes into multistage units does not provide a significant improvement for NEA.

- Vacuum operation is a major interest (even though the practical use of vacuum pumps is not favored in industry due to large footprint and leaks complications).

It has to be stressed that the above conclusions are by no means generic, but limited to the NEA application with polymeric membranes. Future work on high performance materials, showing performances far beyond the trade-off limits [34] is currently in progress, in order to better understand the interplay between materials performances and process engineering. It might be that the conclusions obtained for polymeric membrane materials are completely different when ultrapermeable and/or ultraselective materials are used. Finally, the extension of the methodology to other gas separations applications (e.g. natural gas treatment, hydrogen purification) is obviously also of interest. 
373 Appendix A. 


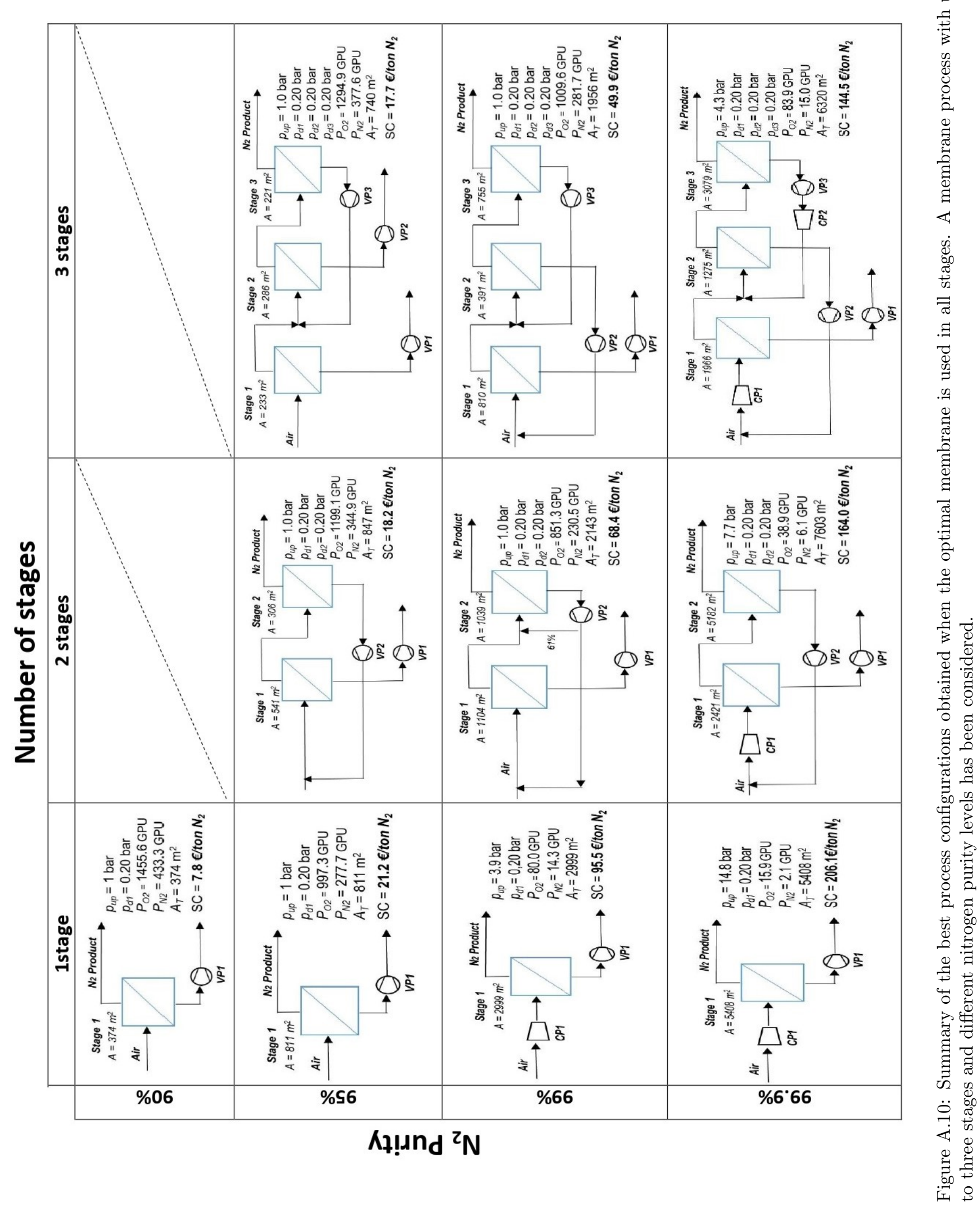




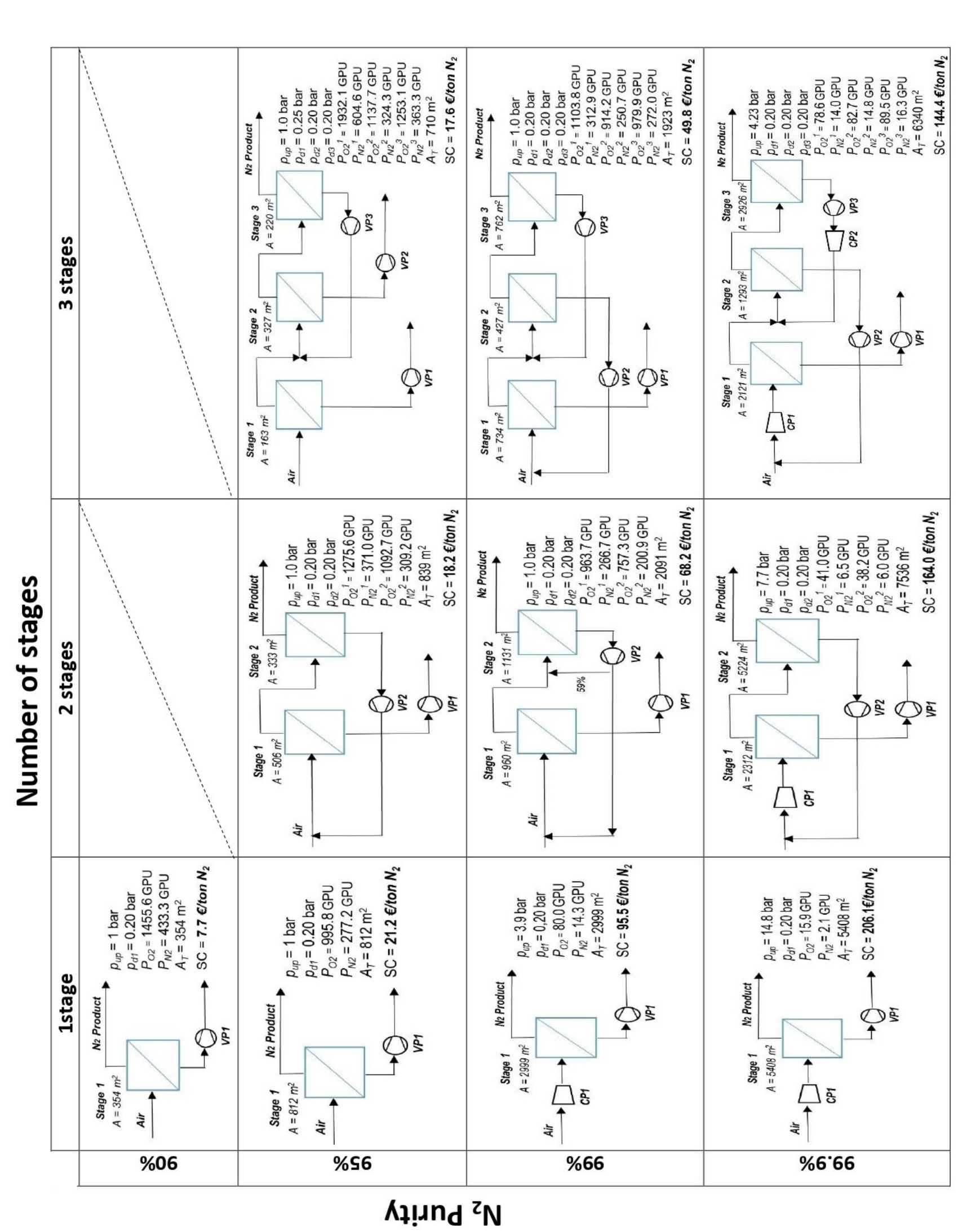

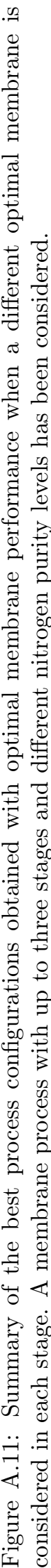




\section{Acknowledgements}

375

376 Research reported in this publication was supported by King Abdullah University of Science 377 and Technology (KAUST \# OSR-2016-CPF-2910). 
a

ICF

$\mathrm{k}$

$\mathrm{K}_{\mathrm{el}}$

$\mathrm{K}_{\mathrm{m}}$

$\mathrm{K}_{\mathrm{mf}}$

$\mathrm{K}_{\mathrm{mr}}$

$\mathrm{M}_{\mathrm{N}_{2}}$

$\mathrm{MDF}_{\mathrm{cc}}$

$\mathrm{MF}_{\mathrm{cc}}$

n

R

$\mathrm{T}$

$\mathrm{t}_{\mathrm{op}}$

$\mathrm{UF}_{2000}$

$\gamma$

$\delta$

$\eta$

$\theta$

$\lambda$

$\nu$

$\phi$
Annuity coefficient for equipment [Dimensionless]

Indirect cost factor [Dimensionless]

Front factor of the $\log -\log$ plot of the Robeson bound [Dimensionless]

Electricity cost factor $[\mathrm{EUR} / \mathrm{kWh}]$

Unit cost of membrane module $\left[\mathrm{EUR} / \mathrm{m}^{2}\right]$

Base frame cost [EUR]

Membrane replacement cost $\left[\mathrm{EUR} / \mathrm{m}^{2}\right]$

$\mathrm{N}_{2}$ Molar mass $[\mathrm{kg} / \mathrm{mol}]$

Compressor module factor [Dimensionless]

Compressor material factor [Dimensionless]

Slop of the $\log$ - log plot of the Robeson bound [Dimensionless]

Ideal gas constant $\left[\mathrm{JK}^{-1} \mathrm{~mol}^{-1}\right]$

Temperature $[\mathrm{K}]$

Operation time per year [h/year]

Update factor [Dimensionless]

Gas expansion coefficient [Dimensionless]

Thickness of the membrane layer $[\mu \mathrm{m}]$

Isentropic compressor efficiency [Dimensionless]

Stage cut of membrane separation [Dimensionless]

Isentropic vacuum pump efficiency [Dimensionless]

Membrane annual replacement rate [Dimensionless]

Mechanical efficiency [Dimensionless] 


\begin{tabular}{|c|c|}
\hline $\mathrm{A}_{\mathrm{m}_{\mathrm{s}}}$ & Area of membrane $\mathrm{s}\left[\mathrm{m}^{2}\right]$ \\
\hline $\mathrm{A}_{\mathrm{T}}$ & Total area of the membrane system $\left[\mathrm{m}^{2}\right]$ \\
\hline CAPEX & Capital expenditures $[\mathrm{EUR}]$ \\
\hline $\mathrm{C}_{\text {cap }}$ & Annual capital costs [EUR/year] \\
\hline $\mathrm{C}_{\mathrm{en}}$ & Annual electricity cost $[\mathrm{EUR} /$ year $]$ \\
\hline $\mathrm{C}_{\mathrm{cc}}$ & Compressor cost $[\mathrm{EUR}]$ \\
\hline $\mathrm{C}_{\mathrm{O} \& \mathrm{M}}$ & Annual operation and maintenance investment cost [EUR/year] \\
\hline $\mathrm{C}_{\text {tot }}$ & Total annual costs $[$ EUR/year] \\
\hline $\mathrm{C}_{\mathrm{vp}}$ & Vacuum pump cost factor $[\mathrm{EUR} / \mathrm{kW}]$ \\
\hline$F^{\text {Ret }}$ & System Retentate flowrate $[\mathrm{mol} / \mathrm{s}]$ \\
\hline $\mathrm{I}_{\mathrm{cc}_{\mathrm{f}}}$ & Feed Compressor investment cost $[\mathrm{EUR}]$ \\
\hline $\mathrm{I}_{\mathrm{Cc}_{\mathrm{s}}}$ & Membrane Compressor investment cost [EUR] \\
\hline $\mathrm{I}_{\mathrm{m}_{\mathrm{s}}}$ & Membrane surface investment cost [EUR] \\
\hline $\mathrm{I}_{\mathrm{mf}}$ & Membrane permanentframe investment cost $[\mathrm{EUR}]$ \\
\hline $\mathrm{I}_{\mathrm{vp}_{\mathrm{s}}}$ & Vacuum pump investment cost [EUR] \\
\hline $\mathrm{M}_{\mathrm{N}_{2} \text { per year }}$ & Annual separated $\mathrm{N}_{2}$ [Tons/year $]$ \\
\hline OPEX & Operational expenditures [EUR/year] \\
\hline $\mathrm{p}_{\mathrm{d}_{\mathrm{s}}}$ & Down stream pressure of membrane s [bar] \\
\hline $\mathrm{p}_{\text {up }}$ & Up stream pressure of all membranes [bar] \\
\hline$P_{j}$ & Permeance of component j [GPU] \\
\hline $\mathrm{SC}_{\mathrm{N}_{2}}$ & Specific $\mathrm{N}_{2}$ production cost $\left[\mathrm{EUR} /\right.$ Ton $\left.\mathrm{N}_{2}\right]$ \\
\hline $\mathrm{X}_{\mathrm{j}}^{\mathrm{Ret}}$ & Fraction of component $\mathrm{j}$ into the system retentate [Dimensionless] \\
\hline $\mathrm{W}_{\mathrm{cp}_{\mathrm{f}}}$ & Feed compression power consumption of membrane s $[\mathrm{kW}]$ \\
\hline $\mathrm{W}_{\mathrm{cps}_{\mathrm{s}}}$ & Permeate compression power consumption of membrane s into $\mathrm{s}_{1}[\mathrm{~kW}]$ \\
\hline $\mathrm{W}_{\text {tot }}$ & Total energy consumption $[\mathrm{kW}]$ \\
\hline $\mathrm{W}_{\mathrm{vp}_{\mathrm{s}}}$ & Vacuum power consumption of membrane s $[\mathrm{kW}]$ \\
\hline$\alpha$ & Selectivity [Dimensionless] \\
\hline
\end{tabular}


References:

[1] H. Heinz-Wolfgang, Industrial Gases Processing, WileyVCH Verlag GmbH \& Co. KGaA, 1st edition, 2008.

[2] W. D. Seider, J. D. Seader, D. R. Lewin, Product \& process design principless: Synthesis, Analysis and Evaluation, John Wiley \& Sons, 2009.

[3] E. Favre, Polymeric membranes for gas separation, in: E. Drioli, L. Giorno (Eds.), Comprehensive Membrane Science and Technology, Elsevier, Oxford, 2010, pp. 155212.

[4] R. W. Baker, Future directions of membrane gas separation technology, Ind. Eng. Chem. Res. 41 (2009) 1393-1411.

[5] J. M. Henis, Commercial and practical aspects of gas separation membranes, in: D. R. Paul, Y. P. Yampolskii (Eds.), Polymeric Gas Separation Membranes, CRC Press: Boca Raton, FL, 1994.

[6] R. Prasad, R. L. Shaner, K. J. Doshi, Comparison of membranes with other gas separation technologies, in: D. R. Paul, Y. P. Yampolskii (Eds.), Polymeric Gas Separation Membranes, CRC Press: Boca Raton, FL, 1994, pp. 531-614.

[7] W. F. Castle, Air separation and liquefaction: recent development and prospects for the beginning of the new millennium, International Journal of Refrigeration 25 (2002) $158-172$.

[8] R. W. Spillman, Economics of gas separation membranes, Chem. Eng. Prog. 85 (1989) 41-62.

[9] R. Mahajan, W. J. Koros, Factors controlling successful formation of mixed-matrix gas separation materials, Industrial \& Engineering Chemistry Research 39 (2000) 26922696.

[10] S. Thomas, I. Pinnau, N. Du, M. D. Guiver, Pure- and mixed-gas permeation properties of a microporous spirobisindane-based ladder polymer (PIM-1), Journal of Membrane Science 333 (2009) 125-131.

[11] H. B. Park, J. Kamcev, L. M. Robeson, M. Elimelech, B. D. Freeman, Maximizing the right stuff: The trade-off between membrane permeability and selectivity, Science 356 (2017).

[12] L. M. Robeson, The upper bound revisited, Journal of Membrane Science 320 (2008) 390-400.

[13] Á. A. Ramírez-Santos, M. Bozorg, B. Addis, V. Piccialli, C. Castel, E. Favre, Optimization of multistage membrane gas separation processes. example of application to CO2 capture from blast furnace gas, Journal of Membrane Science 566 (2018) 346-366. 
[14] R. Bounaceur, E. Berger, M. Pfister, A. A. R. Santos, E. Favre, Rigorous variable permeability modelling and process simulation for the design of polymeric membrane gas separation units: Memsic simulation tool, Journal of Membrane Science 523 (2017) $77-91$.

[15] A. Smith, J. Klosek, A review of air separation technologies and their integration with energy conversion processes, Fuel Processing Technology 70 (2001) 115-134.

[16] R. Prasad, F. Notaro, D. Thompson, Evolution of membranes in commercial air separation, Journal of Membrane Science 94 (1994) 225-248.

[17] R. W. Baker, B. T. Low, Gas separation membrane materials: a perspective, Macromolecules 47 (2014) 6999-7013.

[18] H. Lin, M. Zhou, J. Ly, J. Vu, J. G. Wijmans, T. C. Merkel, J. Jin, A. Haldeman, E. H. Wagener, D. Rue, Membrane-based oxygen-enriched combustion, Industrial \& Engineering Chemistry Research 52 (2013) 10820-10834.

[19] H. M. Ettouney, H. T. El-Dessouky, W. Abou Waar, Separation characteristics of air by polysulfone hollow fiber membranes in series, Journal of Membrane Science 148 (1998) $105-117$.

[20] S. McConnell, Heavy-duty diesel engine nox reduction with nitrogen-enriched combustion air, Argonne National Laboratory \# 02-VTCE-GS-009 (2010).

[21] S. Schmidt, R. Clayton, Dynamic design of a cryogenic air separation unit, Lehigh University.41 p (2013).

[22] M. Yuan, K. Narakornpijit, R. Haghpanah, J. Wilcox, Consideration of a nitrogenselective membrane for postcombustion carbon capture through process modeling and optimization, Journal of Membrane Science 465 (2014) 177-184.

[23] M. Ajhar, M. Follmann, C. Matthias, T. Melin, Membranes producing nitrogen-enriched combustion air in diesel engines: Assessment via dimensionless numbers, Journal of Membrane Science 323 (2008) 105-112.

[24] E. Bozhenko, S. Bozhenko, Computer optimization of a membrane device producing N2 of $98 \%$ purity for preserving museum relics in the hermitage, Gas Separation \& Purification 9 (1995) 31-33.

[25] W. Schell, Commercial applications for gas permeation membrane systems, Journal of Membrane Science 22 (1985) 217-224.

[26] R. Jain, Method for economic evaluation of membrane-based air separation, Gas Separation \& Purification 3 (1989) 123-127.

[27] G. R. Rigby, H. C. Watson, Application of membrane gas separation to oxygen enrichment of diesel engines, Journal of Membrane Science 87 (1994) 159-169. 
[28] B. Bhide, S. Stern, A new evaluation of membrane processes for the oxygen-enrichment of air. II. effects of economic parameters and membrane properties, Journal of Membrane Science 62 (1991) 37-58.

[29] A. Gollan, M. Kleper, The economics of oxygen enriched air production via membranes, IETC - Industrial Energy Technology Conference (1984) Energy Systems Laboratory (http://esl. tamu. edu): Texas A \& M University (http://www.tamu.edu).

[30] S. Haider, A. Lindbråthen, J. A. Lie, M.-B. Hägg, Carbon membranes for oxygen enriched air-part ii: Techno-economic analysis, Separation and Purification Technology 205 (2018) 251-262.

[31] X. Zhu, S. Sun, Y. He, Y. Cong, W. Yang, New concept on air separation, Journal of Membrane Science 323 (2008) 221-224.

[32] I. Purnomo, E. Alpay, Membrane column optimisation for the bulk separation of air, Chemical Engineering Science 55 (2000) 3599-3610.

[33] R. Agrawal, Membrane cascade schemes for multicomponent gas separation, Industrial \& Engineering Chemistry Research 35 (1996) 3607-3617.

[34] W. J. Koros, C. Zhang, Materials for next-generation molecularly selective synthetic membranes, Nature materials 16 (2017) 289. 


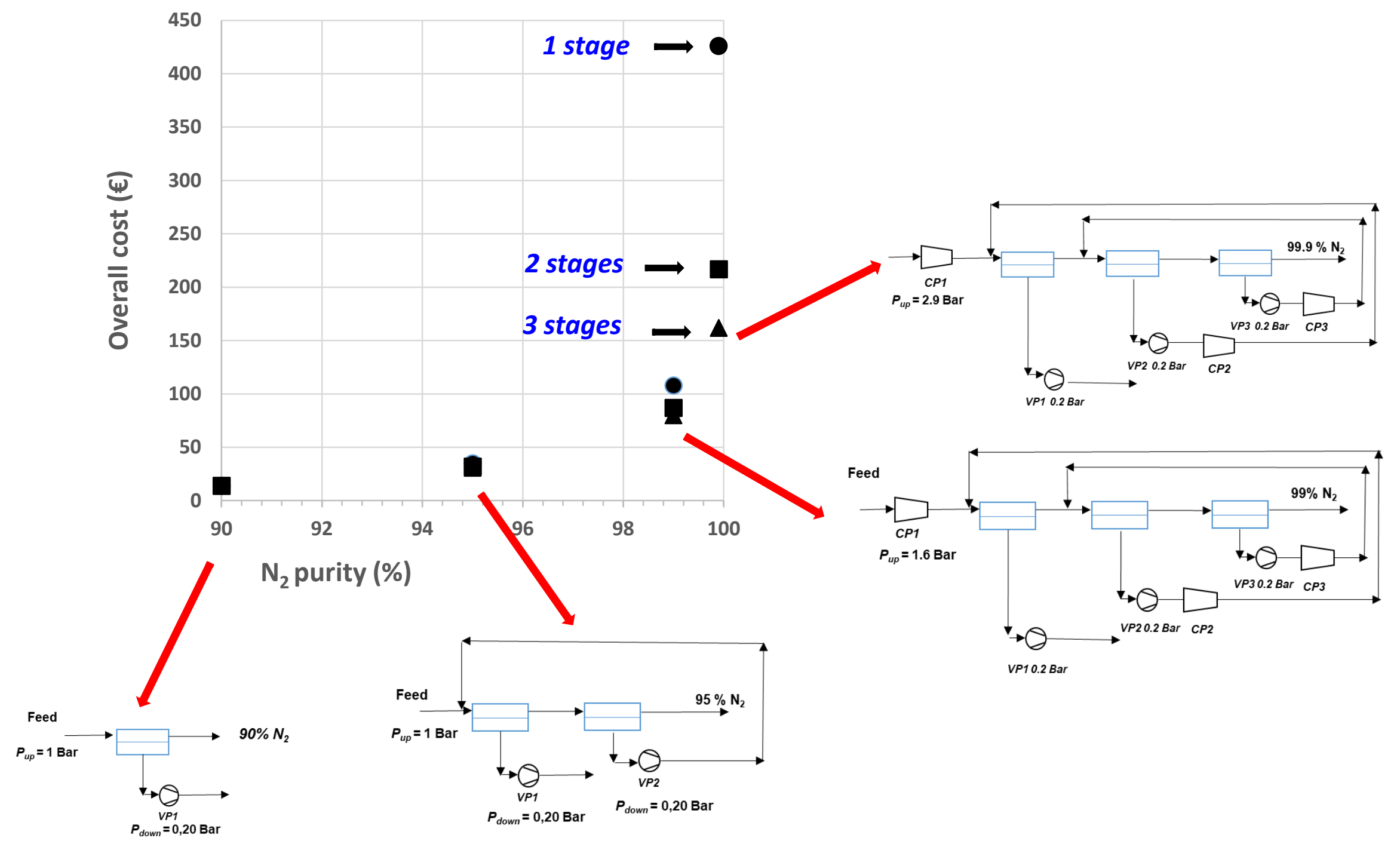

